\title{
Interviews, Focus groups and Delphi techniques
}

By Jennifer Brown

\section{Introduction}

Most applied psychologists are employed in four main areas: clinical, educational, occupational psychology and government service e.g. as prison psychologists (Hartley and Branthwaite, 2000:1). Whether practitioner and/or researcher much of what they do involves exploring people's experiences and behaviour. Nearly eighty years ago, the American psychologist, Gordon Allport, expressed the view that if you want to know something about people's activities the best way of finding out is to ask them. The three methods described in this chapter offer distinct ways of doing this.

Interviews broadly defined are an "interaction in which two or more people are brought together into direct contact for at least one party to learn something from the other" (Brenner, Brown and Canter, 1985:3). A focus group is a facilitated group discussion that is "focused" on a particular topic (Millward, 2000: 304). The Delphi technique structures a group communication process by bringing together a panel of experts to formulate a prediction or set of priorities (Dalkey, 1967:1). By and large the topics of interest addressed by these methods can be characterised as "real world" problems (see Robson and McCarten, 2016 for a comprehensive guide when preparing for and conducting applied research).

The chapter that follows will briefly outline the history, indicate strengths and weaknesses, show how to conduct, and offer some dos and don'ts of these three methods. These are intended as guidance so just following these tips does not necessarily mean the research design, application of the method or conclusions drawn from the analysed data are sound. The requirements for the robustness of the findings (i.e., the demands of reliability and validity) may depend on the purpose of the study and the audience to whom they are disseminated (peer reviewers are likely to be more demanding than a client or research sponsor).

Some preliminary pointers may be helpful before reading the chapter:

- there is a vast accumulated literature on these methods and a chapter such as this can only provide a skeleton outline so other indicative resources will be provided within and at the end of the chapter;

- in choosing a method it must be appropriate to the underlying assumptions of your epistemological approach (very broadly a positivist position in which knowledge is thought to be more objective and factual or constructionist in which knowledge is thought to be more subjective and gained though interaction with an informant);

- the chosen method should permit collection of appropriate data that answers the research question(s);

- the method must meet the needs for the capability and competence of the targeted respondent population;

- it is important to be mindful of how the data generated by these methods are to be analysed (the subject of section three of this book) as part of the decision to opt for one or other, or a combination of, methods; 
- $\quad$ such methods are often employed to address sensitive or pressing topics and may recruit potentially vulnerable groups which impinge on ethical and possibly legal issues (see chapter four for a discussion of these);

- allow sufficient time, become aware of the skills required and other resources ( e.g. equipment, rooms etc.) needed that accompany method of choice.

\section{Origins}

Reliance on oral methods to derive knowledge goes back to the fifth century and Herodotus' History. In modern times one of the first general social science methods textbooks to include a treatise on the research interview was Odum and Jocher in 1926 (quoted in Platt, 2012) and was very much in the fact-finding tradition of social enquiry. By the mid-1950s influenced by counselling and communication theory, the unstructured interview evolved and a tension materialised between the accuracy and precision provided by a uniform administration and asking invariant questions and the experiential non-directive approach typified by Carl Rogers (Platt, 2012). The further move away from the experimental tradition in the 1960s and 70s saw the emergence of social constructionism and the idea that people generating their own meanings of their experience through the giving of "accounts" (see Harré and Secord, 1972). This converged with the development of qualitative analytic methods such as Grounded Theory, Discourse Analysis, Conversational Analysis, Interpretative Phenomenological Analysis and Narrative Analysis (see previous chapter (seven) in this collection and also Howitt, 2011). There are different forms of interviews which Gray (2009) characterises as structured (often used to collect data for quantitative analysis); semi-structured (to allow probing of views and opinions); non-directive (a free form exploration of issues); focussed (which tends to limit responses to a known situation or experience); and informal conversation interviews (relying on spontaneous generation of questions during the interview).

A "deceptively" simple method, the invention of focus groups in social science research is usually credited to Robert Merton in the 1940s, although probably was in use some twenty years prior to this (Wilkinson, 2004). The main use of focus groups prior to the late 1970s was mostly as a market research tool. But during the 1980s this method was adopted by health researchers in areas such as family planning, preventative health interventions and sexual health particularly in relation to HIV/AIDS (Wilkinson, 2004). By the 1990s the method had spread across a wider range of disciplines (such as education, communication and media studies, and feminist research). More recently community-based participative consultations use this method as a way to garner expertise from the lived experiences of locals as well as technical experts across a variety of topics salient to particular localities (Daley et al, 2010).

The Delphi method owes its name to the Delphic Oracle which was consulted to provide authoritative predictions about some major undertaking by the Ancient Greeks (Kennedy, 2004). In its modern manifestation, the RAND Corporation developed this technique initially as a way to forecast the Soviet Union's ballistic missile policy to allow the US military to calculate the number of atomic bombs it would need for its defence (Dalkey, 1967). Classified as a "subjective-intuitive method" Delphi is often employed when there is limited time and some urgency in requiring a steer to solve a pressing, complex problem (Rowell et al, 2015). 
Basically, the technique is aimed at soliciting expert opinion to generate ideas and then establish a measure of agreement over preferred solutions. Widely applied, Delphi has been particularly used in medical and nursing research, community projects, education and management and Government policy application (see Linstone \& Turoff, 2002 for an expostion and examples of this method).

\section{Interviews}

Fundamentally an interview is a conversation in which questions may be posed by the researcher in a structured, semi-structured or unstructured format to gain first hand insights into some topic. Employment of interviews hail from a mixture of positivist and non-positive epistemological positioning to a social constructionist viewpoint of knowledge (Gray, 2009:374). They can be used as the sole data gathering instrument, may a pilot used as a precursor to designing a questionnaire, explore or test hypotheses, or be an adjunct to a questionnaire survey fleshing out richer meanings to closed ended questions ( Rowley, 2012). Choosing a particular type of interview depends on the purpose of the study and the objectives of the research. Kinds of interview vary in terms of the degree to which:

- the interview schedule specifies the questions (ranging from a strictly followed invariant defining and ordering of questions to an aide memoire of themes to be addressed);

- there is a balance of open and closed questions;

- they are interviewer or respondent led;

- they yield a balance of quantitative and qualitative data.

A research interview can be used at virtually any stage of a research enquiry and on any topic. Recruiting respondents is often by some form of purposive sampling, or if a particularly elusive groups of informants the snowball method may be used. This is where a respondent suggests another contact who may be willing to participate in the research (see chapter three in this collection and Atkinson \& Flint, 2001 for a briefing about the technique).

Table 8.1 Summary advantages and disadvantages of the research interview

\begin{tabular}{|c|c|}
\hline Advantages & Disadvantages \\
\hline $\begin{array}{l}\text { - } \text { Flexible } \\
\text { - } \text { Can incorporate other data elicitation } \\
\text { processes (such as psychometric test } \\
\text { or rating scales) } \\
\text { - Rich in-depth data } \\
\text { - } \text { More manageable sample size } \\
\text { - } \text { Respondents potentially more } \\
\text { receptive and informative } \\
\text { - Permits responsivity to social cues } \\
\text { (i.e. non-verbal communication) }\end{array}$ & 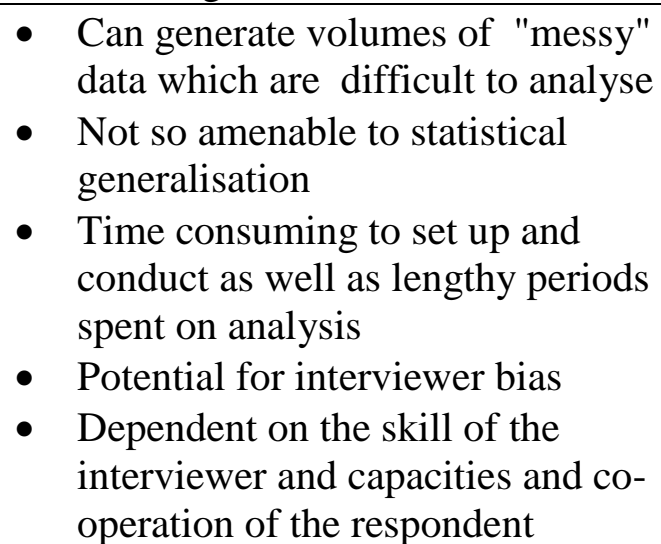 \\
\hline
\end{tabular}

Some general principles for conducting interviews include: 
- $\quad$ pre-preparing the introduction (the explanation for the interview sets the context, tone and style and will influence the conduct of the interview and the type of material elicited);

- establishing the ground rules for your informant that describes the purpose of the research and the conditions pertaining to the conducting of the interview, (e.g., the person can stop at any time and withdraw, signing of an informed consent and reassurances about confidentiality and explaining use the data will be put to);

- testing the comprehensibility and logical sequencing of questions through a pilot;

- knowing how to establish rapport with the interviewee;

- having good listening skills;

- checking that any equipment to record the interview is in good working order;

- making additional preparations if the interview informant is likely to be vulnerable or potentially difficult;

- being aware of and take avoiding measures for any possible sources of interviewer bias (e.g. taking a liking or dislike to a particular informant);

- as a rule of thumb recruiting a minimum of 12 informants;

- assigning at least three hours to transcribe one hour of interview recording.

Often interviews are conducted face to face. Increasingly, telephone interviewing provides an economical alternative but these are not really suitable for sensitive topics or more intensive inquiries. Ideally interviews should have a natural rhythm and a manageable pace.

Table 8.2 List of dos and don'ts when conducting interviews

\begin{tabular}{|c|c|}
\hline Dos & Don'ts \\
\hline $\begin{array}{l}\text { - Adjust the interview schedule in } \\
\text { the light of feedback from the } \\
\text { pilot } \\
\text { - Be thoroughly familiar with the } \\
\text { schedule before starting } \\
\text { interviews proper } \\
\text { - Use probes if insufficient detail is } \\
\text { obtained from initial answer } \\
\text { - Provide non directive nonverbal } \\
\text { encouragement } \\
\text { - Use straightforward ordinary } \\
\text { language in asking questions } \\
\text { - Take tissues and be prepared for } \\
\text { any distress experienced by } \\
\text { informant }\end{array}$ & $\begin{array}{l}\text { - Introduce assumptions before } \\
\text { asking a question } \\
\text { - Use non-verbal cues to imply the } \\
\text { respondent giving the "right" } \\
\text { answers } \\
\text { - Use complicated phrasing or } \\
\text { jargon words } \\
\text { - Use leading questions } \\
\text { - Use general "catch all questions" } \\
\text { (e.g., tell me everything you know } \\
\text { about [the topic of the research] } \\
\text { - Change roles (e.g., adopt } \\
\text { counsellor mode) }\end{array}$ \\
\hline
\end{tabular}

Any interview material is reliant on the informant being able (and willing) to provide the information asked of them. Breakwell (2012) suggests that there is no evidence to suppose that data gathered through an interview is any less reliable or valid than that 
collected by other means. She nevertheless proposes a number of strategies that can help eliminate researcher bias effects such as providing training prior to the conducting of the interviews, using electric recoding rather than note-taking and adopting some form of inter-rater reliability when establishing themes or coding for analysing data.

\section{Focus Groups}

Not tied to any particular theoretical position, the overall objective of focus groups is to get close to the participants' understanding of and perspectives on particular issues rather than generating generalizable data (Millward, 2000). Focus groups can be employed as the main data gathering method, used as a ground clearing pilot to elicit key issues (often as a precursor to a quantitative survey), or as a qualitative supplement to a quantitative survey (Barbour, 2005). The data obtained from a focus group comprise some appreciation of group processes, i.e., the dynamics through which people interact, express and develop their views and the content of views expressed. Thus the recording of evidence might include observations of nonverbal behaviour (such as fidgeting, or facial reactions) and noting para-linguistic features, such as interruptions, overlapping speech and tone of voice (Wilkinson, 2016). In addition, the verbatim content of the discussion forms the corpus of material to be content analysed. Means to record evidence may be by note-taking, audio and/or audio-visual recordings.

Randomised sampling is not really necessary for focus groups, as it is usually a target group that is wanted. Some form of systematic strategy should be employed when making up a focus group and consideration given to screening criteria, e.g., if the discussion was about rape may it be better to have single sex or mixed groups? Sessions probably should last up to one hour but no longer than two hours. Questions may relate to experiences or behaviour, opinions or values, feelings, knowledge, background and demographics (Rosenthal, 2016).

Table 8.3 Summary of the main advantages and disadvantages of focus groups

\begin{tabular}{|c|c|}
\hline Adva & Disaurantages \\
\hline $\begin{array}{l}\text { - } \text { Can tackle sensitive topics } \\
\text { - Good for potentially vulnerable or } \\
\text { hard to reach respondents } \\
\text { - May encourage participation of } \\
\text { individuals otherwise reluctant to talk } \\
\text { one to one } \\
\text { - Give "voice" to ordinary people } \\
\text { involved in controversial issues } \\
\text { - Provide on-going feedback } \\
\text { monitoring some intervention } \\
\text { - Probes underlying attitudes and } \\
\text { beliefs } \\
\text { - Examines issues more holistically } \\
\text { Generates rich data through group } \\
\text { dynamics }\end{array}$ & $\begin{array}{l}\text { - } \text { Can be hijacked by dominant } \\
\text { participant } \\
\text { - } \text { Dependent on the skills of the } \\
\text { facilitator } \\
\text { - Can be chaotic and unwieldy } \\
\text { - } \text { Allows individuals "to hide" by } \\
\text { remaining unengaged } \\
\text { - Data can be unstructured and } \\
\text { voluminous not readily amenable to } \\
\text { summary analysis } \\
\text { - Not suitable for accessing individual's } \\
\text { narratives (as difficult to extricate } \\
\text { from the flow of the group } \\
\text { discussion) } \\
\text { - Not good for measuring attitudes }\end{array}$ \\
\hline
\end{tabular}


- Allows observation of process

- Flexible in terms of location, timing and sampling
- Do not supply data amenable to statistical generalization

- May be driven by the needs of the client not prepared to invest time and money in validating results

Key requirements in running focus groups as a means of data collection include:

- having a facilitator with basic interviewing skills, some knowledge of group dynamics and preferably some experience of running group discussions including people management skills in order to manage difficult, particularly talkative or shy participants;

- preparing well to identify broad parameters of the study, timescale available, number of groups necessary, types of participants and how to recruit them, how to record the data;

- well-developed focus group schedule of questions that will engage participants, uses appropriate terminology, is sufficiently open-ended to allow diverse views to be expressed, flows logically;

- inclusion of other materials such as vignettes, card sorts, pictures, video clips to vary and stimulate discussion;

- pre-writing introduction and ending scripts;

- practicing before running the actual group to ensure the equipment, schedule, timings all work;

- finding an appropriate comfortable and accessible venue;

- supplying suitable refreshments.

At their best focus groups which are welcoming and non-judgmental can be a powerful means to elicit rich and meaningful data (Coté-Arsenault \& MorrisonBredy, 2005). Poorly designed or ill-executed focus group session can be disastrous and impoverish a research study (Barbour, 2005). Kidd and Parshall (2000:296) note that because focus groups evolved outside the mainstream tradition of qualitative research there were no concomitant developments in validity and reliability standards for the data. They provide a helpful discussion of how to enhance the explanatory power of the data.

Table 8.4 List of dos and don'ts when running a focus group

\begin{tabular}{|c|c|}
\hline Dos & Don'ts \\
\hline $\begin{array}{ll}\text { - } & \text { Pilot process } \\
\text { - } & \text { Plan thoroughly } \\
\text { - } & \text { Provide directions to venue } \\
\text { - } & \text { Steer with suitable probes } \\
\text { - } & \text { Encourage all to participate } \\
\text { - } & \text { Anticipate how to handle } \\
\text { distressed/dominant/silent } \\
\text { participants } \\
\text { - } \text { Have a contingency plan if you }\end{array}$ & $\begin{array}{l}\text { - Have groups too big/too small } \\
\text { - Include participants of different } \\
\text { status } \\
\text { - } \text { Become overly engaged in a } \\
\text { particular participant's } \\
\text { contribution } \\
\text { - Answer specific questions } \\
\text { generate by group participants } \\
\text { - Switch role (i.e., fall into }\end{array}$ \\
\hline
\end{tabular}




\begin{tabular}{|l|l|}
\hline need to terminate session & $\begin{array}{l}\text { counselling rather than group } \\
\text { facilitator mode) }\end{array}$ \\
- Over recruit & Allow for between 6-10 \\
participants & $\begin{array}{l}\text { Allow participants to either } \\
\text { dominate or "hide" }\end{array}$ \\
- Identify key roles (moderator, & \\
note taker) & \\
- Have tissues, name labels, pens & \\
\hline
\end{tabular}

Focus groups are helpful in identifying the thinking, perceptions and impressions of a particular group and are especially good when eliciting views of interest groups who may be difficult to access. Well run, they can yield a great deal of informative data but which are not readily generalizable.

\section{Delphi technique}

As the Delphi technique involves both qualitative and quantitative elements, it crosses the methodological divide. The aim of the Delphi method is quite often to generate policy solutions under conditions of uncertainty, pressurised time horizons and where there may be a lack of clarity. As such, they may be of particular benefit to practitioners. Delphi has for example, been used to assess the views of expert providers of services and compared with users as expert recipients (Kennedy, 2004). However the Delphi method is generally viewed as an exploratory technique or as a platform for future research and represents a step in knowledge building.

There are four essential features:

- participating experts are selected by a moderator (researcher), who remain anonymous to each other so that each may freely express their opinion;

- information is reviewed and refined over a number of "rounds" by the moderator;

- the moderator provides controlled feedback of the collective view;

- statistical collation of results.

Given that knowledgeable participants are specially chosen for their expertise some form of purposive sampling is usually adopted; thus inclusion criteria are required. This may involve recruiting an expert with a minority or divergent view in order to explore the full range of opinions. A panel of experts (unknown to each other) is thus created to participate across two or more questionnaire rounds. Data generated usually comprise open-ended material in which relevant issues are identified in the first round. The moderator collates these and constructs a questionnaire survey to allow for some further consideration by panellists in a second round. This is usually in the form of a numerical rating scale of importance, or agreement of some policy position or proposed intervention or evaluation. Here it is important to observe principles of good survey design (see chapter 11) and avoid ambiguous or repetitive items (Iqbal \& Pipon-Young, 2009). A further evaluative round comprises feedback of panellists' scores on the preceding questionnaire items and they are asked to reconsider these in the light of this feedback and indicate whether they wish to change their responses. Basic descriptive statistics are calculated (e.g., percentages, means, standard deviations) to establish the panellists consensus. 
Table 8.5 Summary of advantages and disadvantages of the Delphi Technique

\begin{tabular}{|c|c|}
\hline Advantages & Disadvantages \\
\hline 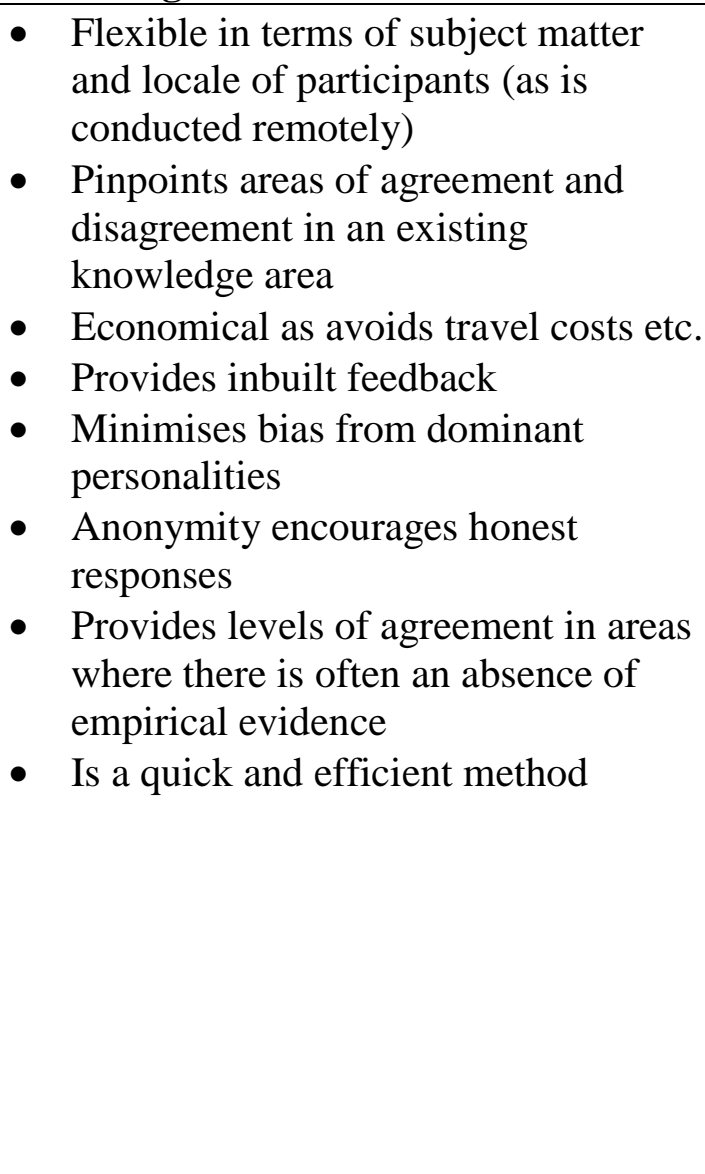 & 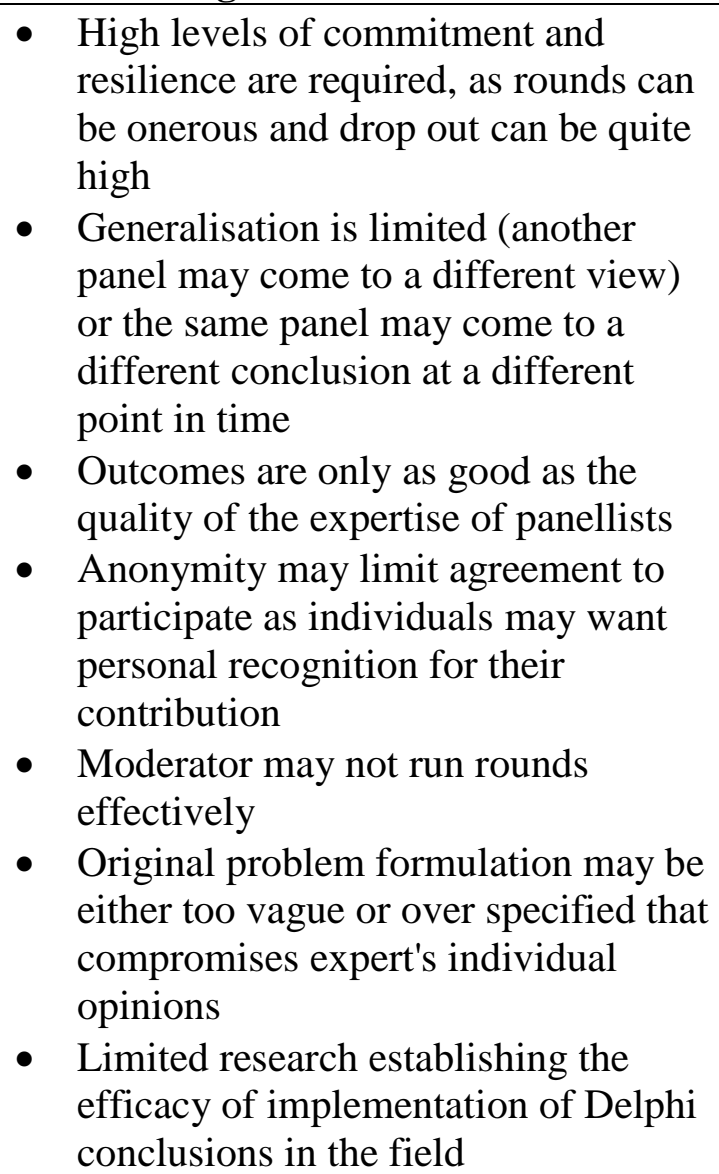 \\
\hline
\end{tabular}

Key requirements in running a Delphi study are:

- Having both qualitative analytic skills to collate idea generated in round one and quantitative skills in questionnaire construction and statistical analysis for subsequent rounds:

- Providing a clear problem specification;

- Establishing clarity of purpose, to establish diversity of opinions on a topic or generating a consensus (divergent views may be an important outcome);

- Deciding on the number of rounds required and timeframe for their execution;

- Careful selection of panellists through specified inclusion (and exclusion) criteria;

- Choice between 10-20 panellists (but no more than 50). Larger panels tend to provide more stable results;

- Give panellists about 2 weeks to respond;

Delphi methods have been increasingly included in the armoury of techniques for evidence based practice (Jorm, 2015). However production of a report or even 
publication of results is in themselves insufficient to guarantee implementation. In planning a Delphi study, it is often helpful to include questions about implementation as one of the questions for the experts to consider.

\section{Table 8.6 List of dos and don'ts when conducting a Delphi panel}

\begin{tabular}{|c|c|}
\hline Dos & Don'ts \\
\hline $\begin{array}{l}\text { - Have a clear objective } \\
\text { - Provide rapid turnaround of } \\
\text { feedback } \\
\text { - Encourage re-assessment of initial } \\
\text { standpoint in the light of } \\
\text { subsequently expressed views by } \\
\text { panellists } \\
\text { - Use a minimum of three } \\
\text { iterations-open ended, collated } \\
\text { questionnaire and final evaluation } \\
\text { rounds } \\
\text { - Where disagreement, ask panellist } \\
\text { to expand their reasoning for their } \\
\text { opinion } \\
\text { Electronic communication most } \\
\text { efficient }\end{array}$ & $\begin{array}{l}\text { - Chose panellists who are simply } \\
\text { knowledgeable rather use the } \\
\text { most qualified individuals } \\
\text { - Chose panellists with variable } \\
\text { levels of knowledge } \\
\text { - Use too few panellists } \\
\text { - Send feedback distorting the } \\
\text { panellists aggregated views trying } \\
\text { to "mould" opinion }\end{array}$ \\
\hline
\end{tabular}

Delphi techniques tend not to employ conventional scientific criteria of reliability and validity (Powell, 2003). Instead "goodness of fit" criteria may be used such as the explicitness of the inclusion criteria for choosing experts. Face validity can be present in terms of the coherence, usefulness and applicability of recommendations.

Additionally or alternatively, comparison of two expert panels considering the same topic may be undertaken.

\section{Conclusion}

Choosing the most appropriate method is an integral part of the research process. Sometimes less experienced researchers may think qualitative methods such as interviewing is easier and quicker than conducting a quantitative survey as there are fewer participants to recruit and use of statistical analyses minimised. Actually designing an interview schedule, focus group protocol or specifying the problem in a Delphi round is exacting and requires considerable skill. Analysing qualitative data is time consuming and often involves subtle and nuanced interpretations. The best advice is to choose the method that most adequately fits the needs of the potential respondents and best serves to answer the research question.

\section{Some further reading}

The compendium of data collection and analytic methods in the edited collection by Glynis Breakwell and colleagues (2012) is an excellent starter text for a good 
overview. David Silverman's (2016) edited book on qualitative methods has comprehensive coverage and includes details of interviewing and focus group methodologies. The Sage handbook of interview research edited by Gubrium and others is a more focussed text with specific chapters providing helpful guidance on conducting and analysing data gathered by means of interviews and focus groups. Whilst directed at nurses and health professionals, Keeney, Hasson and McKenna (2010)Gubrium, J., Holstein, J., Marvasti, A., and McKinney,K.(eds.) The Sage handbook of interviewing research; the complexity of the craft, second edition. Los Angelos: Sage.

Harré, R., \& Secord, P. F. (1972). The Explanation of Social Behaviour. Oxford: Blackwells.

Hartley, J., and Branthwaite, A. (2000) The Applied Psychologist. Buckingham:Open University Press.

Howitt, D.(2011) Using qualitative methods to research offender and forensic patients In Sheldon, K., Davies, J., and Howells, K. (eds.) Research in Practice for Forensic Professionals. Abingdon: Routledge. (pp.132-158)

Iqbal, S., \& Pipon-Young, L. (2009). Methods-The Delphi method--A guide from Susanne Iqbal and Laura Pipon-Young. Psychologist, 22: 598-600.

Jorm, A. F. (2015). Using the Delphi expert consensus method in mental health research. Australian and New Zealand Journal of Psychiatry, 49: 887-897.

Keeney, S., Hassan, F., and McKenna, H. (2010) The Delphi Technique in Nursing and Health Research. Oxford: Wiley.

Kennedy, H. P. (2004). Enhancing Delphi research: methods and results.Journal of Advanced Nursing, 45:, 504-511.

Kidd, P. S., \& Parshall, M. B. (2000). Getting the focus and the group: enhancing analytical rigor in focus group research. Qualitative Health Research, 10: 293-308.

Linstone, H. A., \& Turoff, M. (eds.). (1975). The Delphi Method: Techniques and applications (Vol. 29). Reading, MA: Addison-Wesley.

Accessed $5^{\text {th }}$ September, 2016 at http://s3.amazonaws.com/academia.edu.documents/40866077/delphibook.pdf?AWSA $\underline{\text { ccess KeyId=AKIAJ56TQJRTWSMTNPEA } \& \text { Expires }=1473084643 \& \text { Signature }=\mathrm{gXZr}}$ x0s4F6FqlQZA0kkMKI3OyNI\%3D\&response-content-

disposition=inline\%3B\%20filename\%3DThe_Delphi_Method_Techniques_and_Appl ica.pdf

Millward, L. (2000) Focus groups. In Breakwell, G., Hammond, S., and Fife-Schaw, C. (eds.) Research Methods in Psychology. $2^{\text {nd }}$ ed. London: Sage. (pp 274-292).

Platt, J. (2012) The history of the interview In Gubrium, J., Holstein, J., Marrasti, A., and McKinney, K. (eds.) Sage Handbook of Interview Research; The Complexity of the Craft. $2^{\text {nd }}$ ed. Thousand Oaks, Ca: Sage. 
Powell, C. (2003). The Delphi technique: myths and realities. Journal of Advanced Nursing, 41: 376-382.

Robson, C. and McCarten, K. (2016) Real World Research; a Resource for Users of Social Science Research Methods in Applied Settings. Chichester: Wiley.

Rosenthal, M. (2016). Qualitative research methods: Why, when, and how to conduct interviews and focus groups in pharmacy research. Currents in Pharmacy Teaching and Learning, 8: 509-516.

Rowley, J. (2012). Conducting research interviews. Management Research Review, 35: 260-271.

Silverman, D. (Ed.). (2016). Qualitative research. Los Angeles: Sage.

Wilkinson, S. (2004) Focus groups In Breakwell, G. (ed.) Doing Social Psychology Research. Oxford: BPS/Blackwells. (pp 344-376).

Wilkinson, S. (2016) Analysing focus group data. In D. Silverman (ed.) Qualitative Research: Theory, Method and Practice. $4^{\text {th }}$ ed. London: Sage. (pp 83-100). 